\title{
Aa. Vv., «Revue Montesquieu», n. 8
}

\section{Stefania Carli}

\section{(2) OpenEdition}

\section{Journals}

\section{Edizione digitale}

URL: http://journals.openedition.org/studifrancesi/8918

DOI: 10.4000/studifrancesi.8918

ISSN: 2421-5856

\section{Editore}

Rosenberg \& Sellier

\section{Edizione cartacea}

Data di pubblicazione: 1 octobre 2008

Paginazione: 457

ISSN: 0039-2944

\section{Notizia bibliografica digitale}

Stefania Carli, «Aa. VV., «Revue Montesquieu», n. 8», Studi Francesi [Online], 155 (LII | II) | 2008, online dal 30 novembre 2015, consultato il 13 janvier 2021. URL: http://journals.openedition.org/ studifrancesi/8918 ; DOI: https://doi.org/10.4000/studifrancesi.8918

Questo documento è stato generato automaticamente il 13 janvier 2021.

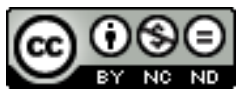

Studi Francesi è distribuita con Licenza Creative Commons Attribuzione - Non commerciale - Non opere derivate 4.0 Internazionale. 


\section{Aa. Vv., «Revue Montesquieu», n. 8}

\section{Stefania Carli}

\section{NOTIZIA}

«Revue Montesquieu», n. 8, 2005-2006, pp. 293.

1 Il presente numero della rivista dedicata a Montesquieu pubblica una serie di studi incentrati sulla questione dell'impero nella produzione letteraria dell'autore, una tematica che, come precisa Céline SPECTOR nell'introduzione (Monstesquieu et l'empire. Introduction, pp. 5-16), non è mai stata particolarmente approfondita dalla critica. La studiosa ricorda che, secondo l'autore dell'Esprit des lois, l'impero nasce da un desiderio di dominio che spesso arreca disagio a coloro che vengono conquistati e nessun vantaggio di rilievo per i conquistatori. Montesquieu distingue due modelli di impero: il primo, come sottolinea sempre Céline SPECTOR (Montesquieu, l'Europe et les nouvelles figures de l'empire, pp. 17-42), è basato sul controllo totale esercitato da un popolo su un altro; il secondo è invece più attento al rispetto della libertà di coloro che sono sottomessi. Per Montesquieu, una possibilità di estendere le relazioni internazionali tra i diversi paesi risiede piuttosto nel commercio (Marco PLATANIA, Dynamiques des empires et dynamiques du commerce: inflexions de la pensée de Montesquieu, 1734-1802, pp. 43-66); egli preferisce infatti, come fa notare Catherine LARRÈRE (L'empire, entre fédération et république, pp. 111-136), l'idea di una sorta di confederazione fondata sullo sviluppo dell'attività commerciale.

2 Come afferma Paul RAHE (Le livre qui ne vit jamais le jour: les "Considérations sur les Romains» de Montesquieu et leur contexte historique, pp. 67-80), il progetto di Montesquieu riguardante la pubblicazione di un'opera dedicata all'analisi dell'impero, in realtà non si concretizzò mai. Ciò nonostante, l'autore viene definito come un vero e proprio imperialista da Michael MOSHER (Montesquieu on Conquest: Three Cartesian Heroes and Five Good Enough Empires, pp. 81-110), che individua nel suo articolo ben cinque tipologie di impero descritte nella produzione letteraria di Montesquieu, il cui pensiero politico, dalla pubblicazione della prima delle Lettres persanes (1721) a quella dell'Esprit des lois 
(1748), è approfondito nella sua evoluzione da Jean TERREL (A propos de la conquête: droit et politique chez Montesquieu, pp. 137-150). Pierre BRIANT (Montesquieu, Mably et Alexandre le Grand: aux sources de l'histoire hellénistique, pp. 151-185) si sofferma invece sulla figura di Alessandro il Grande così come viene vista da Montesquieu e da Mably, trovando nell'analisi del primo il fondamento degli studi ellenistici del diciannovesimo e del ventesimo secolo.

3 A completamento di questo volume della rivista, ci sono poi l'articolo di Jean EHRARD, incentrato sulle citazioni riguardanti l'autore dell'Esprit des lois nel giornale «Le Monde» durante il biennio 2003-2004 (Montesquieu dans «Le Monde» en 2003-2004, pp. 189-197), e una ricca bibliografia curata da Christophe MARTIN (Bibliographie 2004-2005, pp. 201-211) che comprende le pubblicazioni uscite durante gli anni 2004 e 2005. Seguono infine quattordici lectures critiques sugli studi più recenti dedicati alla figura e all'opera di Montesquieu. 